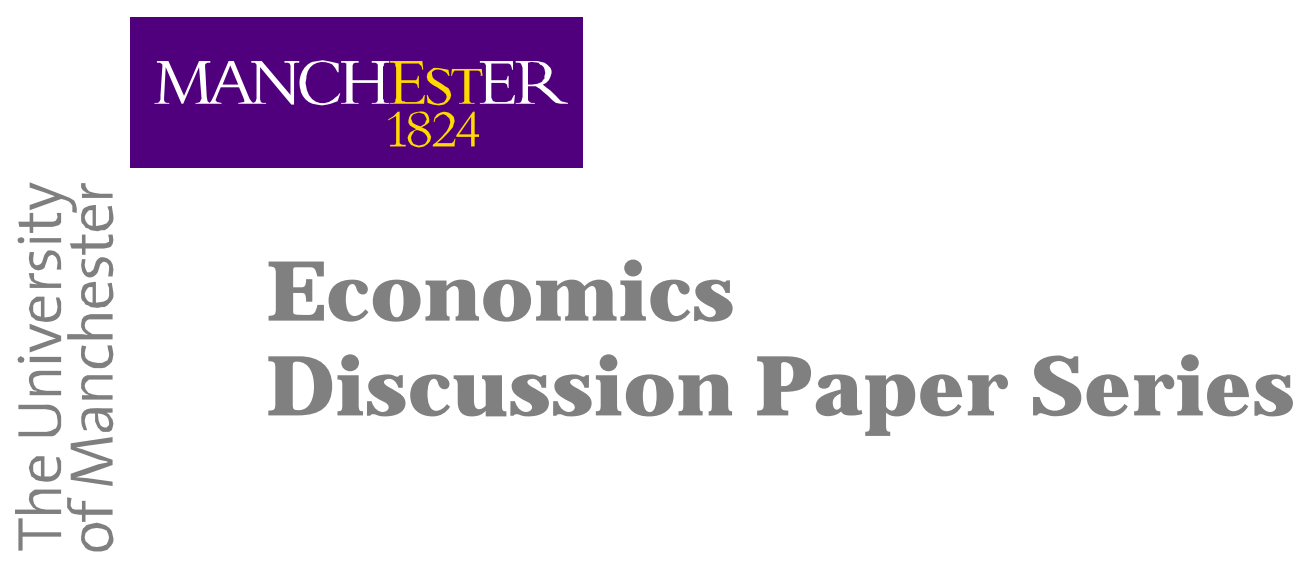

\title{
Changes in the order of integration of US and UK inflation
}

\author{
Andreea Halunga \\ Denise Osborn \\ Marianne Sensier
}

\section{EDP-0715}

Economics

School of Social Sciences

The University of Manchester

Manchester M13 9PL

August 2007 


\title{
Changes in the Order of Integration of US and UK Inflation
}

\author{
Andreea Halunga \\ School of Business and Economics \\ University of Exeter \\ Denise R. Osborn \\ Centre for Growth and Business Cycle Research \\ Economics, School of Social Sciences \\ University of Manchester \\ Marianne Sensier \\ Centre for Growth and Business Cycle Research \\ Economics, School of Social Sciences \\ University of Manchester
}

August 7, 2007

\begin{abstract}
This paper tests US and UK inflation for multiple changes in the order of integration, either from $I(1)$ to $I(0)$ or $I(0)$ to $I(1)$, employing the modified tests of Harvey, Leybourne and Taylor (2006) and repartitioning the sample when a break is found. Our results show that inflation in both countries changes from $I(0)$ to $I(1)$ in the early 1970 s, with a subsequent reversion to $I(0)$ behaviour in the early 1980s. Thus, inflation in these countries has unit root properties only during the 1970s period of high inflation, with behaviour over the last two decades compatible with modern macroeconomic theories that require it to be stationary.
\end{abstract}

Keywords: inflation; structural change.

JEL Classification Codes: C12; C22. 


\section{Introduction}

The stationarity of inflation is a key issue for policymakers, since many central banks now have a target level of inflation. However, since an $I(1)$ variable has infinite variance and crosses a specific value infrequently, such a target is largely meaningless if inflation is nonstationary with a unit root. Stationarity is also important from the perspective of macroeconomic modelling, since the widely used class of so-called New Keynesian models are specified on the presumption that a steady state exists, and this steady state will certainly involve relationships between the levels of (at least) inflation, interest rates and the output gap. There is then a tension between the macroeconomics perspective and the statistical results of standard unit root tests that, over sample periods from the 1970s or earlier, frequently deliver the conclusion that inflation is $I(1)^{1}$.

However, there is substantial evidence that the properties of inflation have changed over time, with recent papers documenting evidence of changing persistence properties including Levin and Piger (2004), Cecchetti and Debelle (2006) and Altissimo et al. $(2006)^{2}$. Such analyses assume that inflation is $I(0)$ and conclusions are then drawn based on tests for structural breaks at one or more unknown dates. However, a deeper and more important issue is whether the order of integration of inflation has also changed, because this issue relates not just to the effectiveness of inflation targeting, but whether it is meaningful to apply such a policy at all. The only paper of which we are aware that explicitly examines this issue is Evans and Wachtel (1993), where these authors estimate a Markov switching model on the assumption that US inflation switches between two regimes, one stationary and the other a unit root process. However, rather than assuming the presence of two such regimes, the tests developed by Busetti and Taylor (2004) and Harvey, Leybourne and Taylor (2006) allow formal testing for a change in the order of integration.

Using these tests, we investigate whether the order of integration of monthly US and UK consumer price inflation has changed over the period 1955-2006. While seasonally adjusted inflation is commonly used in the US, this is not the case for the UK, for which no official seasonally adjusted series is available. Therefore, we analyse UK inflation both seasonally unadjusted and adjusted after application of the X-11 adjustment procedure. Our results show that the order of integration of inflation changes from $I(1)$ to $I(0)$ for both countries in the early 1980s. Repartitioning the sample as proposed by Bai (1997), we also find that both countries experience an earlier break from $I(0)$ to $I(1)$ in the first half of the 1970s. For the US, these results validate the nature of the regimes assumed by Evans and Wachtel (1993).

\footnotetext{
${ }^{1}$ For example, Charemza, Hristova and Burridge (2005) study monthly inflation in 107 countries since the $1950 \mathrm{~s}$, and find that the majority of series would be judged $I(1)$ according to the conventional ADF test applied at a 5\% significance level.

${ }^{2}$ The macroeconomics and econometrics literature differ somewhat in their use of the term "persistence". In the former case persistence is usually measured by the sum of the coefficients in an autoregressive representation of the process, which is typically assumed to be $I(0)$. However, the recent econometric literature (such as Busetti and Taylor, 2004) use the term to distinguish between $I(0)$ and $I(1)$ processes.
} 

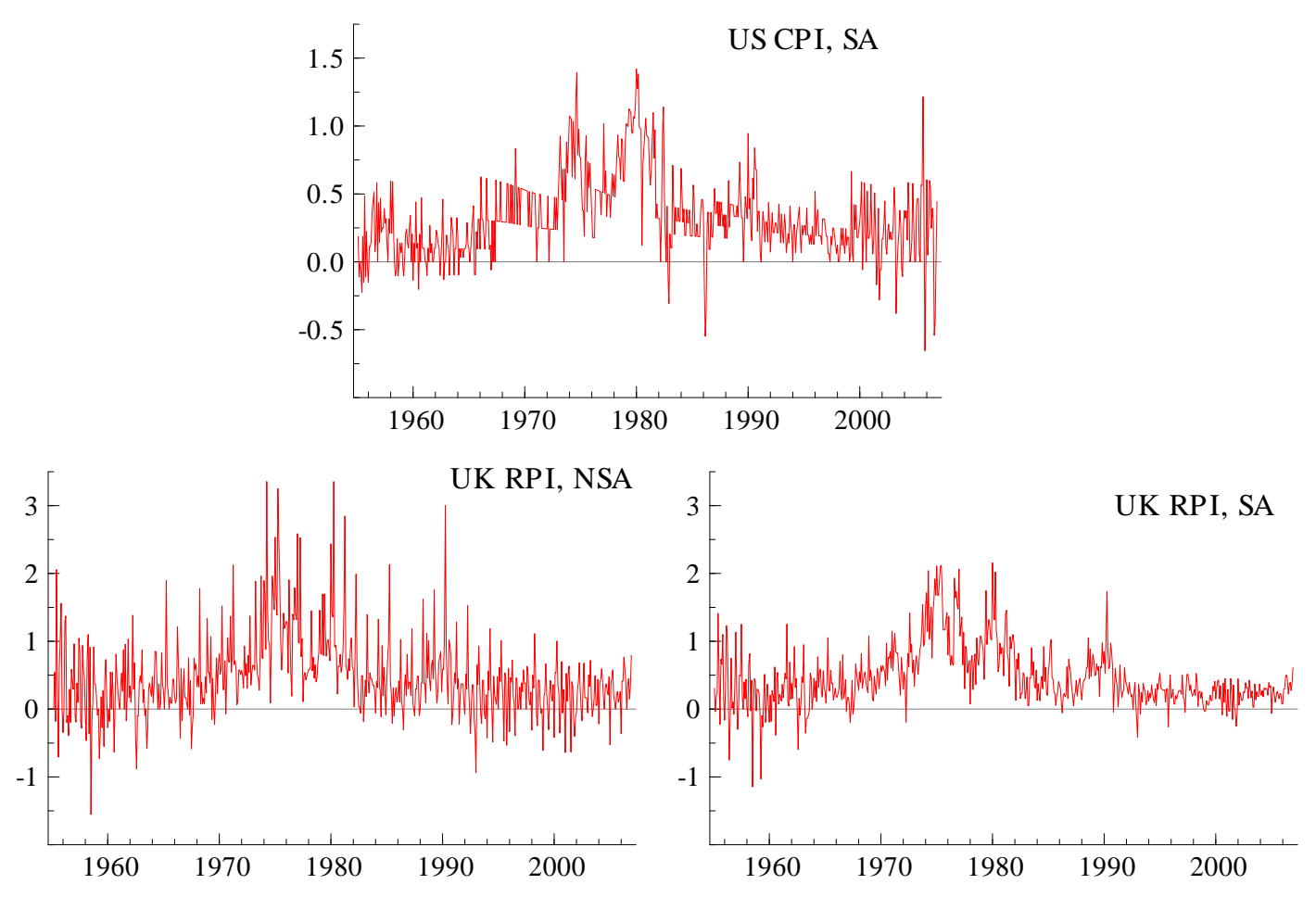

Figure 1: Monthly Inflation for the US and UK

The outline of this paper is as follows. The next section details the data and presents the results of standard unit root tests. Section 3 describes the methodology we employ for testing breaks in the order of integration. The results of these tests for US and UK inflation are presented and discussed in Section 4, while Section 5 offers some conclusions.

\section{Data and Preliminary Analysis}

We employ monthly data over $1955 \mathrm{~m} 1$ to $2006 \mathrm{~m} 12$. The US consumer price index (CPI) is seasonally adjusted (SA) by the Bureau of Labor Statistics, and our data source is the FRED database at the Federal Reserve Bank of St. Louis (http://research.stlouisfed.org/fred2/). For the UK, the not seasonally adjusted (NSA) retail price index from the OECD is used to ensure a long sample, with the SA series obtained by applying the X-11 filter. The SA series for both countries are checked for outliers, with the outliers detected then removed from 
both the SA and (for the UK) NSA series ${ }^{3}$. Monthly inflation is computed as 100 times the first difference of the log series, with resulting monthly inflation growth rates shown in Figure 1. It is clear that both countries experienced high rates of inflation from the mid-1970s to around the mid-1980s.

\subsection{Unit root tests}

Macroeconomic analysis of inflation assumes that the series is $I(0)$. However, this assumption is not supported by standard Augmented Dickey Fuller (ADF) unit root tests, as shown in Table 1. Here all tests include an intercept and those for unadjusted UK inflation data include monthly dummy variables. As well as the entire sample, subsamples commencing at the beginning of each new decade to 2006 are used. According to these results, the conclusion about the stationarity of these series depends on the sample period and (to a lesser extent) the treatment of seasonality. However, in general, both US and UK inflation appear to be stationary over the whole sample, nonstationary for samples beginning in 1960 or 1970, but (after seasonal adjustment in the UK case) stationary for samples beginning in the 1980s or later ${ }^{4}$.

Table 1. ADF unit root tests for inflation

\begin{tabular}{cccc}
\hline Sample & US, SA & UK, NSA & UK, SA \\
\hline $1956 m 3-2006 m 12$ & $-2.939^{b}$ & -2.558 & $-2.983^{b}$ \\
$1960 m 1-2006 m 12$ & -2.690 & -2.419 & -2.740 \\
$1970 m 1-2006 m 12$ & -2.513 & -2.088 & -2.256 \\
$1980 m 1-2006 m 12$ & $-3.743^{a}$ & -2.685 & $-3.024^{b}$ \\
$1990 m 1-2006 m 12$ & $-3.030^{b}$ & -2.685 & $-3.041^{b}$ \\
\hline
\end{tabular}

Note: Superscripts ${ }^{a},{ }^{b}$ denote significance at the $1 \%(-3.44)$ and $5 \%(-2.87)$ significance levels, where the null hypothesis of the ADF test is that the series is $\mathrm{I}(1)$. The order of augmentation in the ADF test regression is 12 lags, selected by minimising AIC.

Therefore, there is a tension between modern macroeconomic analysis that relies on the stationarity of these series and the statistical results that indicate nonstationarity over the period from 1960. Further, Table 1 points to the possibility of the order of integration changing over time. We aim to clarify these properties by examining whether the stationarity properties of inflation

\footnotetext{
${ }^{3}$ The X-11 filter and outlier detection are from a Gauss program made available by Mark Watson and outlined in Stock and Watson (2003). This program uses a fraction of an interquartile range with our threshold multiple set to 4 . Outliers in $1975 \mathrm{~m} 3,1975 \mathrm{~m} 4,1975 \mathrm{~m} 5$ and $1979 \mathrm{~m} 7$ are removed for the UK and in $1973 \mathrm{~m} 8$ for the US, with each outlier replaced by the median of the preceding five observations. The SA series is used for outlier detection to avoid conflating outliers and seasonality. However, once detected, the same correction is applied to the corresponding NSA observation.

${ }^{4}$ The indication of a unit root in NSA inflation for the UK over these latter subsamples in Table 1 may be due to the distortionary effect of the change in the seasonal pattern around 1993 detected by Osborn and Sensier (2004).
} 
have changed over time, using the tests for breaks in the order of integration introduced in the next section.

\section{Methodology}

For testing the null hypothesis of a constant $I(0)$ process against a change in persistence from $I(0)$ to $I(1)$ at an unknown change-point, Kim et al. (2002) and Busetti and Taylor (2004) develop the following statistics

$$
\begin{aligned}
M X & \equiv \sup _{\tau \in\left[\tau_{l}, \tau_{u}\right]} \mathcal{K}_{\tau} \\
M E & \equiv \ln \left\{\int_{\tau \in\left[\tau_{l}, \tau_{u}\right]} \exp \left(\frac{1}{2} \mathcal{K}_{\tau}\right) d \tau\right\}
\end{aligned}
$$

where

$$
\mathcal{K}_{\tau}=\frac{(T-[\tau T])^{-2} \sum_{t=[\tau T]+1}^{T}\left(\sum_{s=[\tau T]+1}^{t} \hat{\varepsilon}_{1, s}\right)^{2}}{([\tau T])^{-2} \sum_{t=1}^{[\tau T]}\left(\sum_{s=1}^{t} \hat{\varepsilon}_{0, s}\right)^{2}}
$$

in which $\hat{\varepsilon}_{0, t}$ and $\hat{\varepsilon}_{1, t}$ are the OLS residuals from the regression of $y_{t}$ on a constant over the periods $t=1, \ldots,[\tau T]$ and $t=[\tau T]+1, \ldots, T$, respectively and $\tau \in(0,1)$. Busetti and Taylor (2004) show that $M X$ and $M E$ are $O_{p}\left(T^{2}\right)$ under a change in persistence from $I(0)$ to $I(1)$, but inconsistent against a change in persistence from $I(1)$ to $I(0)$. They propose to take the reciprocal of (3), denoted $\mathcal{K}_{\tau}^{R}$, and then apply (1) or (2), The resulting statistics, $M X^{R}$ and $M E^{R}$, are $O_{p}\left(T^{2}\right)$ under a change in persistence from $I(1)$ to $I(0)$.

In order to estimate the breakpoint date for a change from $I(1)$ to $I(0)$, Kim et al. (2002) propose

$$
\hat{\tau}=\arg \min _{\tau \in\left[\tau_{l}, \tau_{u}\right]} \Lambda(\tau), \quad \Lambda(\tau)=\frac{([\tau T])^{2} \sum_{t=[\tau T]+1}^{T} \hat{\varepsilon}_{1, t}^{2}}{(T-[\tau T])^{2} \sum_{t=1}^{[\tau T]} \hat{\varepsilon}_{0, t}^{2}}
$$

where $\hat{\varepsilon}_{0, t}$ and $\hat{\varepsilon}_{1, t}$ are defined as previously, whereas the estimator of the breakpoint for a change from $I(0)$ to $I(1)$ is $\tilde{\tau}=\arg \max _{\tau \epsilon\left[\tau_{l}, \tau_{u}\right]} \Lambda(\tau)$.

The above statistics are designed to test under an $I(0)$ null and the Monte Carlo simulations of Harvey et al. (2006) indicate that they are severely oversized when the true process is $I(1)$ throughout. Based on the variable addition approach of Vogelsang (1998), Harvey et al. (2006) propose modified versions of the statistics with the null hypothesis of constant order of integration (either $I(0)$ or $I(1))$ throughout the sample. The modified version of the sup type test statistic of (1) is

$$
M X_{\min }=\exp \left(-b J_{\min }\right) M X
$$


where $J_{\min }=\min _{\tau \in \mathcal{F}} J_{1,[\tau T]}$ and $J_{1,[\tau T]}$ is $T^{-1}$ times the Wald statistic for the joint hypothesis of $\gamma_{k+1}=. .=\gamma_{9}=0$ in the regression

$$
y_{t}=x_{t}^{\prime} \beta+\sum_{i=k+1}^{9} \gamma_{i} t^{i}+u_{t}, \quad t=1, \ldots,[\tau T]
$$

and $b$ is a finite constant such that for a given significance level, $100 \alpha \%$, the asymptotic upper-critical value of the $M X_{\min }$ under either a constant $I(0)$ or $I(1)$ process is identical to the upper-tail $100 \alpha \%$ critical value of $M X$ under the null of a constant $I(0)$. The construction of the test for changes from $I(1)$ to $I(0)$, denoted $M X_{\text {min }}^{R}$, is undertaken in the same way, except that (6) is estimated over $t=[\tau T]+1, \ldots, T$. Analogous modifications are proposed by Harvey et al. (2006) for $M E_{\min }$ and $M E_{\min }^{R}$. If the tests reject for both directions of change, then Harvey et al. (2006) suggest taking the maximum over the statistics, i.e. $\max \left\{M X_{\min }, M X_{\min }^{R}\right\}$ and $\max \left\{M E_{\min }, M E_{\min }^{R}\right\}$.

Under the null hypothesis of no change in the order of integration, we are agnostic as to whether inflation is $I(0)$ or $I(1)$. Therefore, the results presented in the next section use the approach of Harvey et al. (2006). If evidence of a break is uncovered (at the 5 percent significance level), then the date of the break is estimated using the procedure of Kim et al. (2002).

Although the above tests allow only one change in the order of integration over the sample period, we examine the possibility of multiple break points by employing a procedure proposed by Bai (1997) in the context of estimating mean breaks one at a time. In an analogous manner to Bai (1997), the order of integration change tests are applied to the whole sample and, if one or more tests reject the null hypothesis, the sample is split at the estimated changepoint and the tests of change in persistence are performed for each sub-sample. This sequential procedure is repeated until the tests cannot reject the null of a constant order of integration. When all break points have been estimated, a repartitioning is undertaken if an estimated break has been obtained from a (sub)sample containing more than one break. In this case, the estimated change point dates are re-estimated conditional on adjacent break points.

Our analysis follows Leybourne et al. (2006) in testing for a break over the central 60 percent of the relevant (sub)sample, implying a trimming parameter of 0.2 at each end of the subsample. However, in many cases, a change in the order of integration is estimated to occur at an endpoint of the search interval. These results may be unreliable, since they are based on very different implied samples before and after the break, and hence such breaks are discarded ${ }^{5}$.

When applied to NSA data, monthly seasonal dummy variables are included in the test regressions. This does not affect the limiting distribution of the statistic $\mathcal{K}_{\tau}$ in (3), and hence also its generalisations considered above, since

\footnotetext{
${ }^{5}$ Bai and Perron (2003) emphasise that for the usual structural break tests the appropriate "trimming" to apply at the beginning and end of the sample needs to take account of the properties of the data, with a higher trimming parameter suggested in the presence of serial correlation or heterogeneity. Although this issue does not appear to have been studied for integration change tests, the appropriate trimming may be even more important here, since the tests relate to the long-run properties of the data.
} 
Phillips and Jin (2002) show that the limit theory under the null and alternative of the KPSS test (from which $\mathcal{K}_{\tau}$ is derived) is invariant to the presence of seasonal dummies in the regression.

\section{Results for US and UK Inflation}

We now turn to the results for inflation, the key variable associated with monetary policy in the US and UK.

Table 2 shows the results of the modified tests of Harvey et al. (2006) under the null of a constant order of integration, together with estimated change points, for US seasonally adjusted inflation. Wild bootstrap p-values, that are robust against non-stationary volatility effects, are also shown for the tests for a change in integration, as proposed by Cavaliere and Taylor (2006).

Table 2. Tests for a change in persistence for US seasonally adjusted inflation

\begin{tabular}{|c|c|c|c|c|c|c|}
\hline US & $I(0)-I(1)$ & $M X_{\min }$ & $M E_{\min }$ & $I(1)-I(0)$ & $M X_{\min }^{R}$ & $M E_{\min }^{R}$ \\
\hline $1955 \mathrm{~m} 2-2006 \mathrm{~m} 12$ & $1996 \mathrm{~m} 7_{e}$ & $\begin{array}{l}82.65^{a} \\
(0.00)\end{array}$ & $\begin{array}{l}36.47^{a} \\
(0.00)\end{array}$ & $1982 \mathrm{~m} 6$ & $\begin{array}{l}41.87^{a} \\
(0.04)\end{array}$ & $\begin{array}{l}16.37^{a} \\
(0.04)\end{array}$ \\
\hline $1955 \mathrm{~m} 2-1982 \mathrm{~m} 6$ & $1973 \mathrm{~m} 1$ & $\begin{array}{r}181.65^{a} \\
(0.00)\end{array}$ & $\begin{array}{l}84.75^{a} \\
(0.00)\end{array}$ & - & $\begin{array}{c}4.27 \\
(0.24)\end{array}$ & $\begin{array}{l}0.54 \\
(0.33)\end{array}$ \\
\hline 1982m7-2006m12 & $2002 \mathrm{~m} 1_{e}$ & $\begin{array}{l}31.00^{b} \\
(0.03)\end{array}$ & $\begin{array}{l}10.88^{b} \\
(0.04)\end{array}$ & - & $\begin{array}{c}3.76 \\
(0.41)\end{array}$ & $\begin{array}{c}0.58 \\
(0.42)\end{array}$ \\
\hline $1982 \mathrm{~m} 7-2002 \mathrm{~m} 1$ & $1998 \mathrm{~m} 2_{e}$ & $\begin{array}{r}58.69^{a} \\
(0.00)\end{array}$ & $24.81^{a}$ & - & 9.35 & $\begin{array}{l}1.71 \\
(0.25)\end{array}$ \\
\hline $1982 \mathrm{~m} 7-1998 \mathrm{~m} 2$ & $1994 \mathrm{~m} 12_{e}$ & $\begin{array}{l}67.06) \\
(0.00)\end{array}$ & $\begin{array}{l}29.09 \\
(0.00)\end{array}$ & - & $\begin{array}{c}4.45 \\
(0.57)\end{array}$ & $\begin{array}{c}0.54 \\
(0.72)\end{array}$ \\
\hline $1955 \mathrm{~m} 2-1973 \mathrm{~m} 1$ & $1969 \mathrm{~m} 2$ & $\begin{array}{l}29.42^{b} \\
(0.02)\end{array}$ & $\begin{array}{l}11.20^{b} \\
(0.02)\end{array}$ & - & $\begin{array}{l}1.45 \\
(0.87)\end{array}$ & $\begin{array}{c}0.16 \\
(0.94)\end{array}$ \\
\hline${ }^{R} 1973 \mathrm{~m} 2-2006 \mathrm{~m} 12$ & - & $\begin{array}{c}3.82 \\
(0.28)\end{array}$ & $\begin{array}{c}0.14 \\
(0.79)\end{array}$ & $1982 \mathrm{~m} 9$ & $\begin{array}{r}55.07^{a} \\
(0.04)\end{array}$ & $\begin{array}{r}23.08^{a} \\
(0.04)\end{array}$ \\
\hline
\end{tabular}

Notes: Superscripts ${ }^{a},{ }^{b}$ denote significance at the $1 \%, 5 \%$ significance level. Subscripts b and e are beginning and end points respectively. The $\mathrm{MX}_{\min }, \mathrm{ME}_{\min }$ and $\mathrm{MX}_{\min }^{R}, \mathrm{ME}_{\min }^{R}$ denote the modified ratio tests of Harvey, Leybourne and Taylor (2006) for a change from I(0) to $\mathrm{I}(1)$ and from $\mathrm{I}(1)$ to $\mathrm{I}(0)$, respectively. The modified tests are run at the significance level indicated over the subsample period $\tau \in[0.2,0.8]$. Superscript ${ }^{R}$ denotes repartitioning of the sample due to Bai (1997). In brackets the wild bootstrap p-values are reported obtained for 1000 bootstrap repetitions.

The first row of Table 2 uses the full sample and, according to the maximum value of the statistics, the results indicate a change from $I(0)$ to $I(1)$ dated at $1996 \mathrm{~m} 7$ for US inflation. However, this result is disregarded, as this is the end date of the sample used for searching (indicated by $e$ for end point). The change in the opposite direction, at 1982m6, is also significant, and this is adopted as a break. We then proceed to split the sample at this latter date and find a change in persistence from $I(1)$ to $I(0)$ estimated to occur in $1973 \mathrm{~m} 1$. Subsequent to $1982 \mathrm{~m} 6$, however, no reliable break occurs, even when the search interval is reduced using the possible break dates at endpoints. Although checking the sample prior to the 1973 break indicates a significant change from $I(0)$ to $I(1)$ 
at $1969 \mathrm{~m} 2$, this is incompatible with the conclusion over the longer subsample that this change occurs in $1973^{6}$.

The superscript ${ }^{R}$ before the sample date denotes the sequential repartitioning procedure as employed by Bai (1997). When the sample is split at the first significant break date in the sample in 1973 we find that the same change in persistence from $I(1)$ to $I(0)$ is detected, albeit dated three month later in $1982 \mathrm{~m} 9$.

Table 3. Tests for a change in persistence of UK seasonally unadjusted inflation

\begin{tabular}{|c|c|c|c|c|c|c|}
\hline UK & $I(0) \rightarrow I(1)$ & $M X_{\min }$ & $M E_{\min }$ & $I(1) \rightarrow I(0)$ & $M X_{\min }^{R}$ & $M E_{\min }^{R}$ \\
\hline $1955 \mathrm{~m} 2-2006 \mathrm{~m} 12$ & $1973 \mathrm{~m} 8$ & $\begin{array}{c}162.66^{a} \\
(0.00)\end{array}$ & $\begin{array}{l}73.20^{a} \\
(0.00)\end{array}$ & $1981 \mathrm{~m} 4$ & $\begin{array}{c}249.09^{a} \\
(0.00)\end{array}$ & $\begin{array}{c}117.55^{a} \\
(0.00)\end{array}$ \\
\hline $1955 \mathrm{~m} 2-1981 \mathrm{~m} 4$ & $1973 \mathrm{~m} 12$ & $\begin{array}{r}56.85^{a} \\
(0.00)\end{array}$ & $\begin{array}{r}25.14^{a} \\
(0.00)\end{array}$ & $1960 \mathrm{~m} 4_{b}$ & $\begin{array}{l}26.73^{b} \\
(0.02)\end{array}$ & $\begin{array}{l}9.77^{b} \\
(0.01)\end{array}$ \\
\hline 1981m5-2006m12 & - & $\begin{array}{c}2.71 \\
(0.60)\end{array}$ & $\begin{array}{c}0.45 \\
(0.55)\end{array}$ & $1991 \mathrm{~m} 1$ & $\begin{array}{l}18.11^{b} \\
(0.15)\end{array}$ & $\begin{array}{l}5.41^{b} \\
(0.15)\end{array}$ \\
\hline $1955 \mathrm{~m} 2-1973 \mathrm{~m} 12$ & $1970 \mathrm{~m} 3_{e}$ & $\begin{array}{l}16.09 \\
(0.03)\end{array}$ & $\begin{array}{c}4.89) \\
(0.03)\end{array}$ & - & $\begin{array}{l}1.77 \\
(0.90)\end{array}$ & $\begin{array}{c}0.13 \\
(0.98)\end{array}$ \\
\hline${ }^{R} 1974 \mathrm{~m} 1-2006 \mathrm{~m} 12$ & - & $\begin{array}{l}1.10 \\
(0.58)\end{array}$ & $\begin{array}{c}0.06 \\
(0.86)\end{array}$ & $1981 \mathrm{~m} 4$ & $\begin{array}{c}297.71^{a} \\
(0.00)\end{array}$ & $\begin{array}{c}140.95^{a} \\
(0.00)\end{array}$ \\
\hline
\end{tabular}

Notes: see Table 2.

The results for UK seasonally unadjusted inflation are shown in Table 3 . In this case, the strongest test result for the whole sample is for a change in UK inflation persistence from $I(1)$ to $I(0)$, dated here at $1981 \mathrm{~m} 4$. Splitting the sample at this date, a change in persistence from $I(0)$ to $I(1)$ is estimated to occur in $1973 \mathrm{~m} 12$. The repartitioning results confirm the break date of $1981 \mathrm{~m} 4$, and there is no reliable evidence of any break prior to 1973 or subsequent to 1981.

Table 4. Tests for a change in persistence for UK seasonally adjusted inflation

\begin{tabular}{|c|c|c|c|c|c|c|}
\hline UK & $I(0) \rightarrow I(1)$ & $M X_{\min }$ & $M E_{\min }$ & $I(1) \rightarrow I(0)$ & $M X_{\min }^{R}$ & $M E_{\min }^{R}$ \\
\hline $1955 \mathrm{~m} 2-2006 \mathrm{~m} 12$ & $1973 \mathrm{~m} 8$ & $\begin{array}{c}154.87^{a} \\
(0.00)\end{array}$ & $\begin{array}{l}71.78^{a} \\
(0.00)\end{array}$ & $1981 \mathrm{~m} 12$ & $\begin{array}{c}261.19^{a} \\
(0.00)\end{array}$ & $\begin{array}{c}123.84^{\circ} \\
(0.00)\end{array}$ \\
\hline $1955 \mathrm{~m} 2-1981 \mathrm{~m} 12$ & $1973 \mathrm{~m} 12$ & $\begin{array}{c}52.82^{a} \\
(0.01)\end{array}$ & $\begin{array}{r}23.41^{a} \\
(0.01)\end{array}$ & $1960 \mathrm{~m} 5_{b}$ & $\begin{array}{l}40.70^{b} \\
(0.00)\end{array}$ & $\begin{array}{l}16.23^{b} \\
(0.00)\end{array}$ \\
\hline 1982m1-2006m12 & $2001 \mathrm{~m} 6$ & $\begin{array}{l}21.46^{b} \\
(0.01)\end{array}$ & $\begin{array}{l}7.25^{b} \\
(0.01)\end{array}$ & $1990 \mathrm{~m} 11$ & $\begin{array}{l}33.71^{b} \\
(0.09)\end{array}$ & $\begin{array}{l}12.08^{b} \\
(0.09)\end{array}$ \\
\hline $1955 \mathrm{~m} 2-1973 \mathrm{~m} 12$ & $1970 \mathrm{~m} 3_{e}$ & $\begin{array}{l}17.96^{b} \\
(0.04)\end{array}$ & $\begin{array}{l}5.43^{b} \\
(0.05)\end{array}$ & - & $\begin{array}{c}1.12 \\
(0.92)\end{array}$ & $\begin{array}{c}0.08 \\
(0.98)\end{array}$ \\
\hline${ }^{R} 1974 \mathrm{~m} 1-2006 \mathrm{~m} 12$ & - & $\begin{array}{c}0.99 \\
(0.54)\end{array}$ & $\begin{array}{c}0.05 \\
(0.83)\end{array}$ & $1980 \mathrm{~m} 7_{b}$ & $\begin{array}{c}308.22^{a} \\
(0.00)\end{array}$ & $\begin{array}{l}146.26^{a} \\
(0.00)\end{array}$ \\
\hline$R_{1955 \mathrm{~m} 2-1980 \mathrm{~m} 7}$ & $1973 \mathrm{~m} 12$ & $\begin{array}{r}58.67^{a} \\
(0.02)\end{array}$ & $\begin{array}{r}26.10^{a} \\
(0.02)\end{array}$ & - & $\begin{array}{l}14.09 \\
(0.05)\end{array}$ & $\begin{array}{c}3.84 \\
(0.04)\end{array}$ \\
\hline
\end{tabular}

Notes: see Table 2.

Finally, Table 4 shows the results for the SA data for the UK. The same result holds of a change in persistence from from $I(1)$ to $I(0)$, although this is now dated a few months later than with NSA data, at 1981m12, while the earlier change in persistence from $I(0)$ to $I(1)$ is again dated in $1973 \mathrm{~m} 12$. As repartitioning at the estimated 1973 change date leads to an end point estimate for the $I(1)$ to $I(0)$ break, we retain the $1981 \mathrm{~m} 12$ estimate for this date. No

\footnotetext{
${ }^{6}$ Logically, the change previous to that of 1973 would have to be from $I(1)$ to $I(0)$, not vice versa.
} 
significant evidence (at 5 percent) of a change in integration is found prior to $1973 \mathrm{~m} 12$ or after $1981 \mathrm{~m} 12$.

Table 5 summarises our conclusions that inflation persistence changes from stationary to nonstationary in the early 1970s and then back to stationary from early 1980s, for both the UK and US.

Table 5. Summary of breaks dates for inflation

\begin{tabular}{ccc}
\hline Direction & $I(0) \rightarrow I(1)$ & $I(1) \rightarrow I(0)$ \\
\hline US, SA & $1973 \mathrm{~m} 1^{a}$ & $1982 \mathrm{~m} 9^{a}$ \\
UK, NSA & $1973 \mathrm{~m} 12^{a}$ & $1981 \mathrm{~m} 4^{a}$ \\
UK, SA & $1973 \mathrm{~m} 12^{a}$ & $1981 \mathrm{~m} 12^{a}$ \\
Notes: Superscript & ${ }^{a}$ denote significance at the $1 \%$ level.
\end{tabular}

\section{Conclusions}

Our results for the US and UK show that there is a change in inflation persistence from $I(1)$ to $I(0)$ in the early 1980 s. When we split the sample at this date we find a further change in persistence from $I(0)$ to $I(1)$ in the early 1970s. A novel feature of our analysis is the sample repartitioning we apply, which strengthens our findings by showing that the high persistence implied by an $I(1)$ series applies to inflation in these countries only for around ten years. These results clarify those in Busetti and Taylor (2004), who find mixed evidence about the nature and date of a (single) change in the order of integration for US inflation. Further, they provide a sound statistical basis for the results of Evans and Wachtel (1993) that US inflation was nonstationary from the mid-1970s to the mid-1980s.

In one sense our results are reassuring for macroeconomists, in that inflation is now a stationary series and hence the steady-state relationships on which New Keynesian models rely may exist. Further, central banks targeting inflation is a meaningful exercise, since this series is stationary and hence the target may exist as the long-run steady state level of inflation. However, our results also indicate that care is required in empirical analysis, since these US and UK series have not been stationary throughout the sample from the 1960s.

\section{References}

[1] Altissimo, F., Bilke, L., Levin, A., Mathä, T. and Mojon, B., 2006. Sectoral and aggregate inflation dynamics in the euro area. Journal of the European Economic Association 4, 585-593.

[2] Bai, J., 1997. Estimating multiple breaks one at a time. Econometric Theory $13,315-352$. 
[3] Bai, J., and Perron, P. 2003. Computation and analysis of multiple structural change models. Journal of Applied Econometrics 18, 1-22.

[4] Busetti, F. and Taylor, A.M.R., 2004. Tests of stationarity against a change in persistence. Journal of Econometrics 123, 33-66.

[5] Cavaliere, G. and Taylor, A.M.R., 2006. Testing for a change in persistence in the presence of a volatility shift. Oxford Bulletin of Economics and Statistics 68 (s1), 761-781.

[6] Cecchetti, S.G. and Debelle, G. 2006. Has the inflation process changed? Economic Policy, April 2006, pp. 311-352.

[7] Charemza, W. W., Hristova, D. and Burridge, P., 2005. Is inflation stationarity? Applied Economics 37, 901-03.

[8] Evans, M. and Wachtel, P., 1993. Inflation regimes and the sources of inflation uncertainty. Journal of Money, Credit and Banking 25, 475-511.

[9] Harvey, D.I., Leybourne, S.J. and Taylor, A.M.R., 2006. Modified tests for a change in persistence. Journal of Econometrics 134, 441-469.

[10] Kim, J.Y,. Belaire Franch J., Badilli Amador, R., 2002. Corringendum to "Detection of change in persistence of a linear time series". Journal of Econometrics 109, 389-392.

[11] Levin, A.T. and Piger, J.M., 2004. Is inflation persistence intrinsic in industrial economies?, European Central Bank working paper series, no. 334.

[12] Osborn, D.R. and Sensier, M. 2004. Modelling UK inflation: persistence, seasonality and monetary policy. Centre for Growth and Business Cycles Research, University of Manchester, number 46.

[13] Phillips, P.C.B. and Jin, S., 2002. The KPSS test with seasonal dummies. Economics Letters 77, 239-243.

[14] Vogelsang, T.J., 1998. Trend function hypothesis testing in the presence of serial correlation. Econometrica 66, 123-148. 